\title{
Göçmen Gönderilerinin Dış Ticaret Dengesi Üzerine Etkisi: Seçilmiş BDT Ülkeleri İçin Ampirik Bir İnceleme
}

\author{
Doğan UYSAL* Şerife ÖZŞAHİN** ${ }^{* *}$ Gülbahar ÜÇLER***
}

\begin{abstract}
$\ddot{O} Z$
Çalışmak amacıyla gittiği ülkede bir yıldan daha uzun süre kalan göçmenlerin anavatanlarındaki ailelerine gönderdikleri para olarak tanımlanan göçmen havaleleri, gelişmekte olan ülkelerin önemli sermaye kaynaklarindan biridir. IMF Ödemeler Dengesi ve Uluslararası Yatırım Pozisyonu Klavuzu'nda (BPM6) "çalışanlara tazminat ve kişisel tasarruflar" olmak üzere iki ana bileşene ayrılan göçmen havalelerinin hacmi, 2000'li yıllarla birlikte ciddi artış kaydetmiştir. Göçmen gönderileri; doğrudan yabancı yatırım, dış borçlanma veya dış yardımlara kıyasla daha istikrarlı bir yapıya sahip olmasından dolayı özellikle kronik dış açık sorunu yaşayan ülkelerin bu açı̆̆ı finansmanında güvenilir bir kaynak olarak kabul edilmektedir. 2015 yılı Dünya Bankası verilerine göre, dünya genelindeki yaklaşık 600 milyar $\$$ gö̧̧men gönderisinin yaklaşık \%75'i gelişmekte olan ülkelere doğru akmaktadır. En fazla göçmen gönderisi alan ülkeler Hindistan, Çin, Filipinler ve Meksika iken göçmen gönderilerinin GSYIH içindeki payı dikkate alındığında Kırgızistan, Nepal, Tacikistan ve Moldova gibi küçük ve yoksul ülkeler ilk stralara yerleşmektedir.

Bu çalı̧̧ma göçmen gönderilerinin dış ticaret dengesi üzerine etkisini ileri panel veri analiz teknikleri ile incelemekte ve ilgili literatüre ampirik açıdan katkı sağlamayı hedeflemektedir. Çalışma kapsamında Bağımsız Devletler Topluluğu üyesi 6 ülkenin 2002-2016 dönemi verileri kullanılarak diş ticaret açıklarının finansmanında gö̧̧men havalelerinin etkisi araştırılmıştır. Incelenen zaman dilimi ve ülke seçimi, verilerin kesintisiz olması ve erişilebilirliği dikkate alınarak belirlenmiştir. Bu doğrultuda öncelikle panelde yer alan ülkeler arasında yatay kesit bağımlılığının varlığı araştırılmış ve yapılan analiz ile paneli oluşturan ülkeler arasinda yatay kesit bağımsızllğg olduğu tespit edilmiştir. Bu bulguya dayanarak değişkenlerin durağanlık analizi ve uzun dönem katsayı tahmininde birinci nesil yöntemler kullanılmıştır. Pesaran, Shin ve Smith (1999) PMG (Pooled Mean Group) tahmincisi ile ulaşılan uzun dönem katsayılar göçmen gönderilerinin dış ticaret dengesini Azerbaycan'da pozitif, Moldova ve Tacikistan'da negatif yönde etkilediğini göstermiştir.
\end{abstract}

Anahtar Kelimeler: Göçmen Gönderileri, Dlş Ticaret Dengesi, PMG Tahmincisi.

Jel Sınıflandırması: C33, F22, F24

\section{The Impact of Remittances on the Balance Of Foreign Trade: An Empirical Review of Selected CIS Countries}

\begin{abstract}
Remittances are defined as the money sent by the immigrants who have been working in a foreign country for more than a year to their families in their homeland. They are one of the major capital resources of developing countries. The volume of remittances which are divided into two components as "compensation for employees and personal savings" in the IMF Balance of Payments and International Investment Position Manual (BPM6) has seen a considerable increase since the

\footnotetext{
*Prof.Dr., Manisa Celal Bayar Üniversitesi, İ̈BF İktisat Bölümü, dogan.uysal@ cbu.edu.tr

${ }^{* *}$ Dr.Öğr. Üyesi, Necmettin Erbakan Üniversitesi, SBF İktisat Bölümü, sozsahin@konya.edu.tr

*** Doç.Dr.,Ahi Evran Üniversitesi, İ̈BF İktisat Bölümü, gulbahar.ucler@ahievran.edu.tr

$\mathrm{Bu}$ çalışma, 16-18 Nisan 2018 tarihlerinde Kırgızistan-Bişkek’te düzenlenen Uluslararası Orta Asya Sempozyumu'nda sunumu yapılan tebliğin gözden geçirilmiş ve yeniden düzenlenmiş halidir.
} 
2000s. Remittances are considered to be a reliable source particularly for countries with a chronic foreign deficit as they have a more stable structure compared to foreign direct investment, foreign borrowing or foreign aid, and thus countries may use remittances to finance deficits. According to the 2015 World Bank data, approximately 75 percent of about $\$ 600$ billion of remittances worldwide flows into developing countries. The countries receiving the highest amount of remittance are India, China, Philippines, and Mexico. However, small and poor countries like Kyrgyzstan, Nepal, Tajikistan and Moldova are in the first place when the share of remittances within GDP is taken into account.

This study examines the effect of remittances on balance of foreign trade using advanced panel data methods and thus aims to contribute to the relevant literature empirically. Within the scope of the study, the effect of remittances on the financing of foreign trade deficit was explored using the data for six-member countries of the Commonwealth of Independent States for the 2002-2016 period. The time period and countries selection were determined by considering the availability and accessibility of data. To this end, first, the presence of cross-sectional dependence among the countries in the panel was investigated and the analysis asserted cross-sectional independence among the countries in the panel. Based on this finding, first generation methods were used in the stationarity analysis of variables and long-run coefficient estimation. Long-run coefficients obtained through Pesaran, Shin and Smith (1999) PMG (Pooled Mean Group) estimator showed that remittances are a significant variable that affects balance of foreign trade positively in Azerbaijan and negatively in Moldova and Tajikistan.

Keywords: Remittances, Balance of Foreign Trade, PMG Estimator.

JEL Classification: C33, F22, F24

\section{GİRIŞ}

İşçilerin uluslararası hareketleri yeni bir olgu olmamakla birlikte geçtiğimiz son yıllarda kalkınma önlemleri üzerine yeni bir bakış açısı getirmiştir. Özellikle son on yıl içinde işçilerin uluslararası dolaşımı anavatanlarına gönderdikleri para nedeniyle yerel kalkınma için bir fırsat olarak görülmeye başlanmıştır. Yurt dışında çalışan işçiler tarafından ailelerine gönderilen nakit akımlarının hacminde görülen artış, bu fonların ekonomik kalkınmanın kaynağ olabilme derecesini araştıran yeni bir literatür ortaya çıkarmıştır (Adams ve Page, 2003; Chami vd., 2003; Ratha, 2004; Sorensen, 2004; Shaw, 2006).

Dünya Bankası verilerine göre 2015 yılında tüm dünyada göçmen gönderileri 600 milyar doları aşmıştır. Dünya genelinde 600 milyar dolar olan bu gönderilerin 441 milyar doları gelişmekte olan ülkelere gönderilmiştir. Bu tutar tüm göçmen gönderilerinin yaklaşı \% $\% 5$ 'ine eşittir. 2016 yılı resmi rakamlarına göre en fazla göçmen gönderisi alan ülkeler Hindistan (62.7 milyar \$), Çin (61.0 milyar \$), Filipinler (29.9 milyar \$), Meksika (28.5 milyar \$) ve Pakistan (19.8milyar \$)' dır. ${ }^{1}$ Diğer yandan göçmen gönderilerinin GSYİH içindeki payı, gelişmekte olan 25 ülkede \%10'dan daha fazladır. GSY İH içindeki payı dikkate alındığında en fazla göçmen gönderisi alan ülkeler Kırgızistan, Nepal, Liberya, Haiti, Tacikistan ve Moldova'dır. 2016 yılı rakamlarına göre ${ }^{2}$ Kırgızistan'ın aldığı göçmen gönderisi GSYIH'sinın \%34,5'ine, Nepal'de \%29,7'sine, Haiti'de \%27,8'ine, Tacikistan'da \%26,9'una ve Moldova'da \%21,7'sine eşittir. Bu oranlar göçmen gönderilerinin bu

\footnotetext{
${ }^{1}$ Migration and Development Brief 27, April 2017.

${ }^{2}$ International Monetary Fund; World Bank World Development Indicators. 
ülkeler açısından ne kadar önemli bir fon girişi olduğunu açık bir şekilde göstermektedir.

Göçmen gönderilerin hacminde yaşanan bu artış, son dönemde gönderilerin ekonomik kalkınma aracı olarak görülme nedenini açıklamaktadır. Göçmen gönderileri özellikle gelişmekte olan ülkelerin ekonomik büyüme ve kalkınmasına pozitif yönde bir katkı sağlarken aynı zamanda kronik dış ticaret açığı yaşayan ülkeler için bu açıkların kapatılmasında önemli ve güvenilir bir finansman kaynağı olmaktadır. Göçmen gönderileri doğrudan yabancı yatırımlardan sonra en büyük ikinci döviz kaynağıdır. Diğer yandan bu gönderileri diğer finans kaynaklarından ayıran en önemli özelliği ise ekonomik ve finansal krizlere karşı daha dirençli olması ve resesyon dönemlerinde dahi yüksek dalgalanma yaşamamasıdır. Büyük bir bölümünün alturuistik nedenlere dayanması, göçmen gönderilerini özellikle gelişmekte olan ülkeler için istikrarlı bir döviz kaynăg 1 yapmaktadır. Shakur (2012)'e göre kronik dış ticaret açığı yaşayan ülkelerin borç seviyesi yüksselmesine karşın düşük kredi notu nedeniyle borçlanma kaynakları da zayıflamaktadır. Bu bağlamda Bouhga-Hagbe (2004), göçmen gönderilerinin kısa dönemde alıcı ülkedeki döviz kıtlığını azaltarak kronik ödemeler dengesi açıklarını azalttığını savunmaktadır. Yabancı para birimi üzerinden yapılan gönderiler, döviz kıtlığı yaşayan ülkelerde kısa dönem için dış ticaret dengesini pozitif yönde etkilerken uzun dönemde Hollanda Hastalığı'na neden olabilmektedir. Hollanda Hastalığı'nın temel nedeni alıcı ülkede yaşanan döviz bolluğu nedeniyle ulusal paranın aşırı değerli hale gelmesidir. Ulusal paranın aşırı değerlenmesi ise ithalat maliyetini düşürmenin yanı sıra ülkenin yurt dış1 rekabet gücünü de zayıflatacaktır. $\mathrm{Bu}$ durumda uzun dönemde ithalat artacak ve diş ticaret dengesi negatif yönde etkilenecektir. Alıcı ülkenin göçmen havaleleri ile artan yerli talebi kendi üretim gücü ile karşılaması halinde gönderiler ekonomik büyümeye ve istihdama katkı sağlayacak ancak göçmen dövizlerinin ekonominin üretim kapasitesinden daha yüksek oranda bir talep oluşturması durumunda ise ithalat artacaktır.

$\mathrm{Bu}$ çalışma GSYIH'ya oranı dikkate alındığında en fazla göçmen gönderisi alan Bağımsız Devletler Topluluğu üyesi ülkelerde göçmen gönderilerinin dış ticaret dengesi üzerine etkisini araştırmaktadır. Bu amaç doğrultusunda kesintisiz verisine ulaşılabilen altı ülkenin 2002-2016 dönemi verileri ile ekonometrik analiz yapılmıştır. Çalışmada giriş bölümünü takiben birinci bölümde konuyla ilgili literatür çalışmaları ve bu çalışmaların ulaştığı temel bulgulara yer verilmiştir. İkinci bölümde Bağımsız Devletler Topluluğu üyesi altı ülkede göç hareketleri ve göçmen gönderilerinin hacmine ilişkin açıklamalar yapılmıştır. Tahmin edilecek regresyon denklemi ve veri setinin açıklandığı üçüncü bölümün ardından dördüncü bölümde ekonometrik model ve ampirik bulgulara yer verilmiştir. Kısa bir değerlendirmenin yapıldığı sonuç bölümü ile çalışma tamamlanmaktadır.

\section{LITERATÜR TARAMASI}

Göçmen gönderilerinin ekonomik etkilerini inceleyen literatür, genellikle gönderilerin gelir dağılımı, yoksulluk, ekonomik büyüme ve dış ticaret dengesi üzerindeki etkilerine odaklanmaktadır. Göçmen gönderileri gelişmekte olan ülkelerde düşük ve orta gelirli hane halkının önemli bir gelir kaynağı olduğu için 
gönderilerin refah seviyesini artırdığı görüşü tartışmasız kabul görmektedir. Taylor (1999) ABD'den Meksika'ya yapılan gönderilerde her 100 dolarlık artışın, toplam gelirde 1,78 dolar artışa yol açtığını ifade etmektedir. Ayrıca Ahlburg (1996), Taylor ve Wyatt (1996) ve Taylor (1999) göçmen gönderilerinin gelir eşitsizliğini azaltıcı etki yaptı̆̆ yönünde ampirik kanıtlar elde etmişlerdir. Rosser (2008) göçmen gönderilerinde $\% 10$ oranında bir artışın ülkedeki yoksulluğu $\% 3,5$ oranında azaltacağını savunmaktadır. Acharya ve Gonzalez (2012) ise Nepal örneğinde göçmen gönderilerinin fakirlik ve gelir eşitsizliği üzerine etkisini incelendikleri çalışmalarında göçmen gelirlerinin koşullu olarak hem fakirliği hem de gelir eşitsizliğini azaltmada etkili birer araç olduğunu savunmaktadırlar.

Leon vd. (2001) 11 Orta ve Doğu Avrupa ülkesi üzerine yaptıkları çalışmada, göçmen gönderilerinin ülkenin yatırım seviyesini artırdığı yönünde bulgular elde etmişlerdir. Nsiah ve Fayiss (2013) Afrika, Asya ve Latin Amerika'da bulunan 64 ülke için 1987-2007 dönemi verilerini kullanarak göçmen gönderileri ile ekonomik büyüme arasındaki ilişkiyi incelemişlerdir. Çalışmanın sonucunda modele dahil edilen tüm ülkelerde gönderilerin ekonomik büyümeyi pozitif yönde etkilediğine dair bulgulara ulaşılmıştır. Yine, Adams ve Page (2005), Acosta vd. (2007) göçmen havalelerinin birçok gelişmekte olan ülkede ödemeler dengesini pozitif yönde etkilediğini bunun yanı sıra tasarruf, tüketim, beşeri ve fiziksel sermaye yatırımları yoluyla da ekonomik büyümeyi artırdığını savunmaktadırlar.

Literatürde göçmen gönderilerinin ekonomik büyüme üzerinde yaratacağ 1 olumsuz etkilere dair kanitlar da mevcuttur. Amuedo-Dorantes ve Pozo (2004), Lopes vd. (2007), diğer sermaye akımları gibi göçmen gönderilerinin de alıcı ekonomilerde reel döviz kurunun değerlenmesine neden olabileceğine ve dolayısıyla ticarete konu olan sektörlerden ticarete açık olmayan sektörlere kaynak aktarımına yol açabileceğine dikkat çekmektedirler. Öte yandan göçmen geliri elde eden bireylerin tüketim malları için artan talepleri iç üretim kanalları ile desteklenmezse kısa dönemde bu gönderiler ithalatın finansmanı için kullanılacak ancak takip eden dönemlerde enflasyonist bir etkileşime neden olabilecektir. Kısacası göçmen gönderileri ekonominin üretim kapasitesinden daha fazla oranda talep artı̧̧ yaratıyorsa bu durum nihayetinde enflasyona yol açacaktır. Örneğin Mısır'da göçmen gönderileri nedeniyle tarım arazisi fiyatları 1980-1986 yılları arasında \%600 oranında artmıştır (Adams, 1991). Amuedo-Dorantes ve Pozo (2004), Lopez vd. (2007) diğer sermaye akımları gibi göçmen havalelerinin de alıcı ekonomilerde reel döviz kurunu değerlendirebileceğini ve dolayısıyla kaynakları ticarete konu olan sektörlerden ticarete konu olmayan sektörlere yönlendirebileceğini (Hollanda Hastalı̆̆ı) belirtmektedir. Yine Lipton (1980), Brown ve Ahlburg (1999) düşük gelirli ülkelerde göçmen gönderilerinin ekonomik büyüme ve verimliliği baltaladığını savunmaktadırlar. Çünkü bu ülkelerde göçmen gönderileri üretken yatırım alanlarından ziyade yabancı mallara karşı olan talep artışına yol açmaktadır. Fuentes ve Herrera (2007), Lopez vd. (2007), El Salvador, Guetemala, Meksika ve Latin Amerika'da göçmen gönderilerinin döviz kurunu artırdığına yönelik bulgular elde etmişlerdir. 
Göçmen gönderilerinin ekonomik büyümeye etkisi analiz edilirken üzerinde durulması gereken en önemli husus, gönderilerin giriş yaptığı ülkede hangi amaçla kullanıldığıdır. Göçmen gönderilerinin pozitif etkileri üzerine yoğunlaşan literatür, gelişmekte olan ülkelerde göçmen gönderisi alan aile bireylerinin belirli bir refah seviyesine ulaşana kadar bu gönderileri tüketim, sağlik hizmetleri ve gayrimenkul alımı için kullanıldığı yönünde hemfikirdir (Lowell ve de la Garza, 2000). Göçmen gönderilerinin verimli yatırım alanlarına yönlendirilmesi durumunda ekonomik kalkınma üzerinde yaratacağı pozitif etki artacaktır. Yine bazı çalışmalar, göçmen gönderilerinin tüketim amaçlı kullanılmasının çoğaltan etkisi (multiplier effect) yaratacağını ve ekonomik büyümeyi destekleyeceğini savunmaktadırlar.

Göçmen gönderilerinin ödemeler dengesi üzerine etkisi literatürde en çok tartışılan konular arasındadır. Göçmen gönderileri alıcı ülkede döviz kıtlığını azaltarak kronik ödemeler dengesi açıklarını dengeleyebilmektedir. Bouhga-Hagbe (2004) Fas için yaptığ çalışmada, göçmen gönderilerinin neredeyse dış ticaret açığının tamamını kapattığını ve cari hesapta gözlemlenen fazlalığı açıkladığını savunmaktadır. Göçmen gönderileri ödemeler dengesi üzerinde diğer finansal kaynaklardan (dış yardım, doğrudan yatırım ve borçlanma) daha olumlu etkiye sahiptir. Çünkü bu gönderilerin kullanımı, yüksek ihracat içeriğine sahip belirli yatırım projelerine bağlı değildir, faiz ödemesi yoktur ve geri ödeme gerektirmez. Tüm bunlara ek olarak, göçmen gönderileri diğer sermaye girişlerine kıyasla çok daha istikrarlı bir yabancı kaynaktır ve bazı ülkeler için periyodik olmayan bir karakter sergilemektedir (Buch vd., 2002; Buch ve Kuckulenz, 2004; Nayyar, 1994). Bu nedenle gelişmekte olan ülkeler ödemeler dengesi üzerinde belirgin ve tahmin edilebilir olumlu etkileri olan göçmen gönderilerinin miktarını artırabilmek için bazı düzenlemeler yapmaktadırlar. Ancak bu gönderilerin değerlendirilme şekli, alıcı ülkedeki üretim, enflasyon ve ithalat üzerinde yaratacağı etkiyi belirlemektedir. Göçmen gönderilerinin neden olduğu ek talebin yerli üretimin genişletilmesi yoluyla karşılanması bu noktada önemli bir faktördür. Yerel arzın oluşan ek talebe cevap verme esnekliği, göçmen gönderilerinin pozitif istihdam etkilerinin ya da negatif enflasyon etkilerinin olup olmayacağını ve ek ithalatın gerekip gerekmeyeceğini belirleyen en önemli faktördür. Göçmen gönderilerinin ekonominin üretme kapasitesinden daha fazla bir talep yaratması ithalat artışına neden olmaktadir.

Diğer yandan göçmen gönderileri tasarruflar kanalı ile de diş ticaret dengesi üzerinde etkili olmaktadır. Tasarruf kanalı yoluyla etkileme ise, göçmen gönderilerinin büyük bir bölümü göçmen aileleri tarafından finansal araçlarla değerlendirildiğinde gerçekleşmektedir. $\mathrm{Bu}$ mevduatlar kurumların yurtiçi üretimlerini finanse etme kabiliyetlerini yükseltmekte ve ithal edilen ürünlerin yerli ikamelerinin tedarikini artırmakta veya ihracatı teşvik etmektedir. Her ikisi de mevcut bir ticaret açığının azalmasına yardımcı olmaktadır (Kandil ve Mirzaie, 2008). Ancak daha önce bahsedildiği üzere, göçmen gönderileri yoluyla uyarılan ek talep, yerel çıktı artışı ile desteklenemez ise tüketimdeki artış enflasyonist 
olacaktır ve ithalat artışını teşvik ederek dış ticaret dengesini olumsuz yönde etkileyecektir.

Chami vd. (2003)'e göre, yüksek göçmen gönderisi alan ülkelerde ticarete konu olmayan sektörlerin genişlemesi uzun dönemde uluslararası rekabet gücünü düşürmektedir. $\mathrm{Bu}$ durumda ihracat azalacak ve ithal mallara olan talep artacaktır. Dolayısıyla göçmen gönderileri uzun vadede dış ticaret dengesi üzerinde olumsuz bir etki yapacaktır. Okodua ve Olayiwola (2013) 30 Sahra-altı Afrika ülkesi için göçmen gönderilerinin diş ticaret dengesi üzerine etkilerini inceledikleri çalışmalarında 2002-2011 dönemi verilerini kullanmışlardır. Çalışmadan elde edilen bulgulara göre incelenen ülkelerde göçmen gönderilerinin dış ticaret dengesi üzerinde negatif ancak istatistiksel olarak anlamsız bir etkisi söz konusudur. Dolayısıyla Okodua ve Olayiwola (2013) incelenen ekonomilerde sürdürülebilir bir dış ticaret dengesi sağlama hedefi için göçmen gönderilerinin yararlı olmayacağını düşünmektedirler. Yine, Farzanegan ve Hassan (2015) 11 Orta Doğu ve Kuzey Afrika ülkesinde göçmen gönderilerinin dış ticaret dengesi üzerine etkisini 19922012 dönemi verileri ile araştırmışlardır. Çalışmadan elde edilen bulgulara göre, seçilmiş ülkelerde göçmen gönderisi girişleri hane halkı tüketim harcamalarını artırarak ithalatı tetiklemekte ve dış ticaret açığını artırmaktadır. Ancak literatürde bu konuda tam bir fikir birliği mevcut değildir. Birçok çalışma göçmen gönderilerinin ithalatı tetikleyici etkisi görüşüne katılmamaktadır. $\mathrm{Bu}$ araştırmacılara göre ithalat eğilimi, ekonominin genel gelişimi, tüketim ve yatırım malları üretiminde yapısal bir değişiklik ya da uluslararası iş bölümünün bir sonucu olarak artabilir. El-Sakka ve McNabb (1999) faiz ve enflasyon oranlarının göçmen gönderileri üzerindeki etkilerini analiz ettikleri çalışmalarında gönderiler yoluyla finanse edilen ithalatın yüksek gelir esnekliğine sahip olduğunu savunmaktadırlar. Gençler ve Çiftçi (2012), Türkiye üzerine yaptıkları çalışmada, göçmen gönderilerinin ithalatı finanse etme ve dış ticaret açığını azaltma üzerindeki etkisini incelemişlerdir. Çalışmadan elde edilen bulgulara göre, göçmen gönderileri Türkiye'de ihracat ve üretim artışına katkıda bulunmak yerine tüketim ve ithalatı artırmaktadır.

\section{BAĞIMSIZ DEVLETLER TOPLULUĞUNDA GÖÇ HAREKETLERİ VE GÖÇMEN GÖNDERILERININ HACMİ}

Küreselleşmeyle beraber ortaya çıkan ulaşım ve iletişim alanındaki gelişmeler göçmen hareketlerini ve bilgi alış-verişini kolaylaştırırken, yine bu süreçte, az gelişmiş ve gelişmekte olan ülkelerin yoksullaşması göçmen sayısının artmasındaki en önemli etkenler olmuştur.

2016 y1lında gelişmekte olan ülkelere akan göçmen gönderileri, 2015 yılında \%1'lik azalmanın ardından tekrar \% 2,4 oranında gerileyerek 429 milyon dolar olarak gerçekleşmiştir. Uzun bir dönemdir ilk kez resmi göçmen gönderilerinin hacmi iki yıl ard arda azalma yaşamıştır. Avrupa, Rusya Federasyonu ve Körfez İşbirliği Konseyi (Gulf Cooperation Council) ülkelerinin zayıf ekonomik büyüme performansı, birçok ülkenin uygulamaya koyduğu döviz kuru kontrolleri ve düzenlemeleri ile göçmen karşıtı politikalar resmi göçmen gönderilerinin hacminin daralmasına neden olan faktörler arasındadır. Avrupa ve 
Orta Asya ülkelerine gönderilen havalelerin 2016 yılında yaklaşık \%4,6 oranında azaldığ 1 tahmin edilmektedir. Rusya Federasyonu'nda düşük petrol fiyatları ve uluslararası yaptırımların oluşturduğu ekonomik daralma ve Euro'nun dolar karşısında değer kaybetmesi bu düşüşte etkili olmuştur. Diğer yandan riskten arındırma gibi yapısal kısitlamalar (uluslararası muhabir bankalar, para aklama ve mali suç risklerinden kaçınmak amacıyla para transfer operatörleri üzerindeki kısıtlamalar) göçmenlerin ülkelerine para gönderme maliyetlerini artırmaktadır. Bu nedenle göçmen gönderilerinin bir kısmı resmi olmayan yollarla transfer edilmektedir. Ancak yüksek gelirli ve gelişmekte olan ekonomilerin ekonomik toparlanma süreci ile 2017 için olumlu görünüm veren göstergeler nedeniyle 2017 yılında gelişmekte olan ülkelere giden göçmen havalelerinin yaklaşık \%3,3 oranında artarak 444 milyon dolara ulaşması beklenmektedir.

Meksika-ABD sınırı dünyanın en büyük göç koridoru olmakla birlikte bunu Rusya-Ukrayna ve Bangladeş-Hindistan takip etmektedir. GSYİH içindeki payı dikkate alındığında, 2011 yılından bu yana en yüksek göçmen gönderisi alan ülkeler (gönderilerin \%90'dan fazlası Rusya Federasyonu ve Kazakistan'dan olmak üzere) Tacikistan ve Kırgızistan'dır. Yine bir BDT üyesi ülkesi olan Moldava ise 2016 yılı içinde GSYIH'sının \%21,7'si oranında göçmen geliri elde ederek bu ülkeler arasında 7. sıraya yerleşmiştir. ${ }^{3} 2015$ yılının ortalarından itibaren Kırgızistan, Tacikistan ve Özbekistan (toplamda 45 milyondan daha az bir nüfusa sahip ülkeler) vatandaşları, Rusya Federasyonundaki 11 milyon resmi kayıttı yabanıının yaklaşık üçte birini oluşturmaktadır. $\mathrm{Bu}$ üç ülkenin vatandaşları aynı zamanda Kazakistan'da da resmi kayıtlı yabancıların en büyük bölümüdür. Tacikistan, Özbekistan ve Kırgızistan başta olmak üzere Rusya'ya yapılan işgücü göçü 2000'li yılların başında geniş çaplı bir olgu haline gelmeye başlamıştır. Nihayet 2013 yılında zirveye ulaştığında, Özbekistan'ın 2,7 milyon; Tacikistan'ın 1,2 milyon ve Kırgızistan'ın 600.000 vatandaşı Rusya'da göçmen olarak çalışmaktadır. ${ }^{4} \mathrm{Bu}$ ülkelerde yaşanan hızlı demografik değişim, yapısal yoksulluk, Rusya'nın ucuz emek talebi ve Rusya emek piyasasına kolay erişim gibi birçok etken göçmenlerin sayısını artırmaktadır. Üstelik işgücünün bu dolaşımı, göçmen gönderileri yoluyla ek bir gelir kaynağı oluşturması nedeniyle bölgedeki hükümetler tarafından da desteklenmeye başlanmıştır.

Mevcut veriler bu göç ve havale akışlarının daha az varlıklı BDT ülkeleri için yoksulluğun azaltılmasında önemli bir rol oynadığını göstermektedir. Hane halkı bütçe anket verilerine göre Kırgızistan' da göçmen gönderilerinin yoksulluk oranını yaklaşık \%6-7 puan azalttığı görülmektedir. ${ }^{5} 2015$ yılı rakamlarına göre, Kırgızistan kişi başına düşen 1.015 dolar gelir düzeyi ve kişi başına düşen 1.025 dolar yatırım ile Asya'nın en yoksul beş ülkesinden biridir. Yaklaşık 5,7 milyon nüfusa sahip ülkede, 2015 yılı rakamlarına göre yaklaşık 738.232 Kırgız göçmenin

\footnotetext{
${ }^{3}$ Migration and Development Brief 27, April 2017.

${ }^{4}$ Federal Migration Service of the Russian Federation:

http://www.fms.gov.ru/fms/activity/stats/Statistics/Svedenija_v_otnoshenii_inostrannih grazh

${ }^{5}$ Labour Migration, Remittances, and Human Development in Central Asia, Eurasian Development Bank
} 
\%77'si Rusya'da, \%11'i Almanya'da ve başka Avrupa ülkelerinde çalışmakta ve yüksek miktarda göçmen gönderisi akışı sağlamaktadırlar.

2016 yılı verilerine göre 6,2 milyar dolar göçmen havalesi ile Ukrayna bölgede en yüksek göçmen gönderisi alan ülkedir. 2,5 milyar dolar göçmen gönderisi ile Özbekistan ikinci; 2,2 milyar dolar ile Kırgızistan üçüncü sırada yer almaktadır. 2013 yılında Özbekistan'ın aldığı göçmen havalesi miktarı 6,7 milyar dolar iken bu rakam üç yıl sonra yaklaşı üçte birden daha fazla oranda azalmıştır. Yine Azerbaycan, Türkmenistan ve Tacikistan'ın aldığı göçmen gönderisi miktarı dramatik bir şekilde düşüş göstermiştir. ${ }^{6}$

Teorik yaklaşımlar ve ampirik bulguların yanı sıra değişkenlerin zaman içindeki seyri göçmen gönderileri ve dış ticaret dengesi arasındaki ilişki hakkında bilgi verebilmektedir. Bu amaçla analize dahil edilen altı BDT ülkesine ait veriler kullanılarak Şekil 1 oluşturulmuştur.

Şekil 1: Dış Ticaret Dengesi ile Göçmen Gönderilerinin Zaman İçindeki Seyri

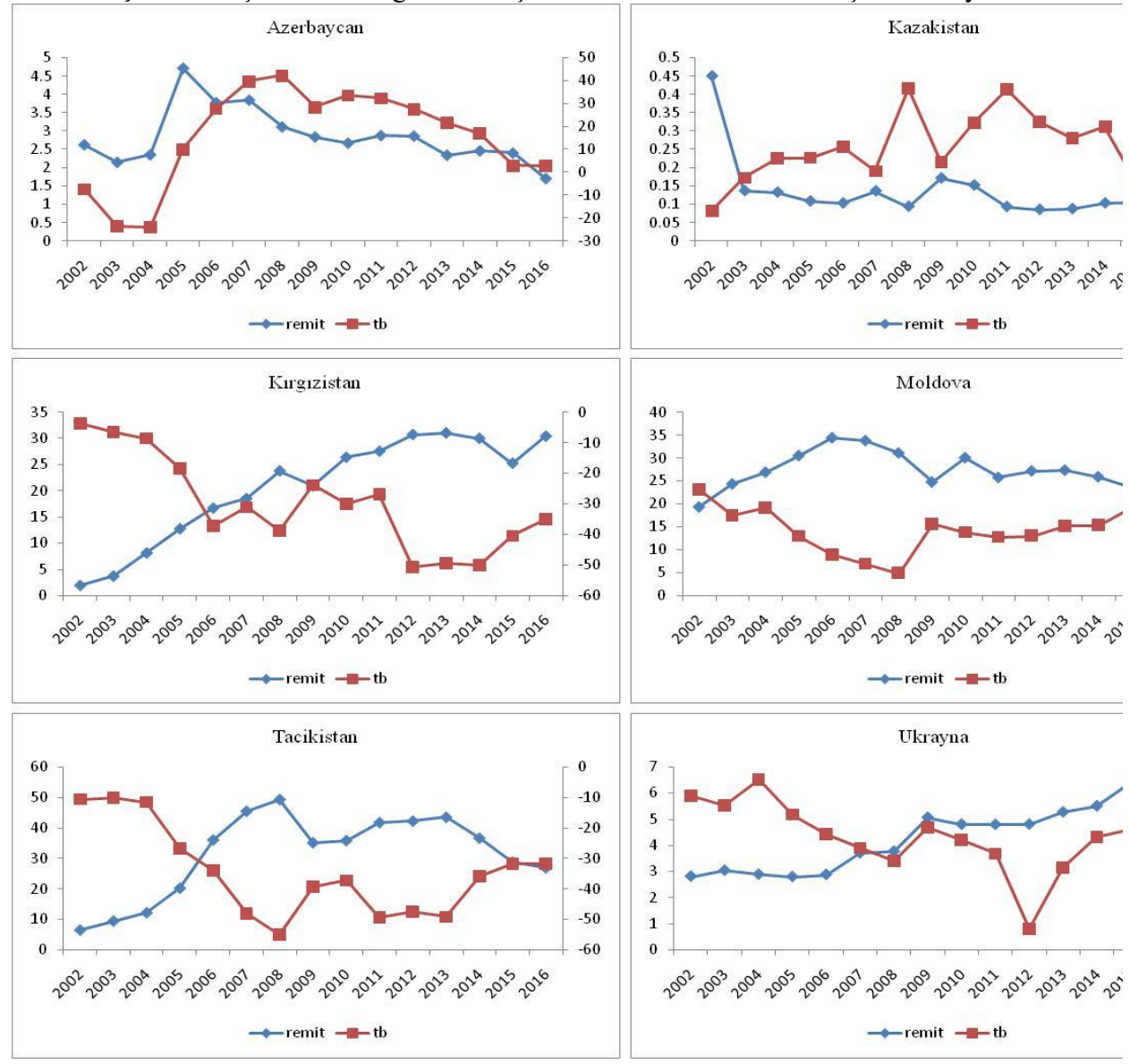

Kaynak: Yazarlar tarafından oluşturulmuştur. remit göçmen gönderilerini, tb ise dış ticaret dengesini temsil etmektedir.

${ }^{6}$ International Monetary Fund; World Bank World Development Indicators 
Şekil 1'de analize dahil edilen altı ülkede diş ticaret dengesi ve göçmen gönderilerinin zaman içinde sergilediği performans görülmektedir. Şekiller incelendiğinde, Azerbaycan'da göçmen gönderileri ile dış ticaret dengesi arasında pozitif yönlü bir ilişki olduğu görülmektedir. Kazakistan'da 2003 y1lında oldukça keskin bir azalmanın ardından göçmen gönderilerinin seyrinde genel anlamda büyük bir değişiklik görülmezken Kırgızistan'da göçmen gönderilerinin hacmi sürekli olarak artmıștır. Kırgızistan'da göçmen gönderisi girișleri, dıș ticaret açığını beraberinde getirmektedir. Moldova'da yine göçmen gönderileri artışı beraberinde dış ticaret açığını getirirken 2013 yılından sonra göçmen gönderilerin miktarında yaşanan azalmaya paralel olarak dış ticaret açığının da düşmeye başlaması dikkat çekicidir. Tacikistan, göçmen gönderileri ile dış ticaret dengesi arasında negatif ve güçlü bir korelasyonun varlığına ilişkin ön bilgi sunarken Ukrayna'nın dış ticaret dengesinde en belirgin kırılma 2012 yılında gerçekleşmiştir. 2012 yılında dış ticaret açığ 1 keskin bir şekilde artarken aynı yıl göçmen gönderilerinde belirgin bir kırılma yaşanmamıştır.

Değişkenlerin zaman içindeki seyrine bakılarak bu ülkelerde göçmen gönderilerinin dış ticaret dengesi üzerinde etkili olduğu yönünde kesin bir yargıya varmanın yanıltıcı olabileceği göz ardı edilmemelidir. $\mathrm{Bu}$ nedenle çalışmada yalnızca göçmen gönderileri ve diş ticaret dengesinin seyri incelenmemiş, bunu yanı sıra dış ticaret dengesi ve göçmen gönderileri arasındaki ilişki ekonometrik yöntemler ile araştırılmıştır.

\section{EKONOMETRIK MODEL VE VERI SETI}

$\mathrm{Bu}$ çalışma, Bağımsız Devletler Topluluğuna üye altı ülkede göçmen gönderilerinin dış ticaret dengesi üzerinde yarattı̆̆ 1 etkiyi test etmektedir. Panel veri seti, Azerbaycan, Kazakistan, Kırgizistan, Moldova, Ukrayna ve Tacikistan'1 kapsamaktadır. Kesintisiz verilerin elde edildiği zaman dilimi 2002-2016 olduğu için ekonometrik analiz bu dönemi kapsamaktadır. Çalışmada tahmin edilecek uzun dönem regresyon denklemi Eşitlik 1'de gösterilmiştir.

$$
T B_{i t}=\alpha_{i}+\beta_{1 i} R E M_{i t}+\beta_{2 i} G_{R O W T H}+\beta_{3 i} E X C_{i t}+\beta_{4 i} R E M * F I N D E V_{i t}+\varepsilon_{i t}
$$

Eşitlikte $i$ yatay kesit birimi olan ülkeleri, $t$ zaman boyutunu, $\varepsilon_{i t}$ ise hata terimini ifade etmektedir. Uzun dönem denkleminin bağımlı değişkeni $T B, i$ ülkesinin toplam ihracat ve ithalat değerlerinin farkı alınarak hesaplanan dış ticaret dengesidir. Çalışmanın temel bağımsız değişkeni REM ise $i$ ülkesine giriş yapan toplam göçmen gönderilerinin GSYİH içindeki payını temsil etmektedir. Ayrıca ekonometrik analizlerde ihmal edilen değişkenin yol açacağı sapmalı sonuçlardan kaçınmak (omitted variable bias) ve modelin tahmin gücünü artırmak için dış ticaret dengesinin önemli belirleyicileri olarak kabul edilen bazı kontrol değişkenler de regresyona dahil edilmiştir. Bu değişkenlerden GROWTH kişi baş1 GSYİH artış hızını, EXC ise ilgili ülkede ulusal paranın ABD doları karşısındaki değerini gösteren resmi döviz kurunu ifade etmektedir. Ayrıca ülkenin finansal gelişmişlik düzeyini temsil etmesi için özel sektöre verilen kredilerin GSYİH içindeki payı FINDEV değişkeni ile modelde yer almaktadır. REM * FINDEV etkileşim terimi, göçmen gönderilerinin bankacılık sektörü kredilerinin ikamesi olup olmadığını belirlemek üzere oluşturulmuştur. 
Dünya Bankası WDI (2016) veri tabanından derlenen tüm değişkenler herhangi bir dönüşüm yapılmaksızın ampirik analizde kullanılmıştır. Yatay kesit bağımlılığı, birim kök, eş-bütünleşme testleri ve parametre tahmini için EViews 10, Gauss 10 ve STATA 14 paket programlarından yararlanılmıştır. Uzun dönem denkleminde yer alan değişkenlere ilişsin ayrıntılı açıklamalar Tablo 1'de yer almaktadır.

Tablo 1: Değişkenlere Ait Açıklamalar ve Veri Kaynakları

\begin{tabular}{|c|c|c|}
\hline Değişken & Değişkenin tanımı & Veri kaynağı \\
\hline $\mathrm{TB}$ & $\begin{array}{l}\text { Dış ticaret dengesi (Mal-hizmet ihracat ve ithalatı arasındaki } \\
\text { farkın GSYIH'ya oranı }\end{array}$ & World Bank, \\
\hline REM & Ülkeye gelen göçmen gönderilerin GSYİH içindeki payı & World \\
\hline GROWTH & Yıllık kişi başı GSYİH büyüme oranı & Development \\
\hline EXC & $\begin{array}{l}\text { Ulusal paranın ABD doları karşısındaki değerini gösteren } \\
\text { resmi döviz kuru }\end{array}$ & $\begin{array}{l}\text { Indicators } \\
\text { (WDI) }\end{array}$ \\
\hline REM $*$ FINDEV & $\begin{array}{l}\text { Etkileşim terimi (ülkeye gelen göçmen gönderileri ile özel } \\
\text { sektör kredilerin çarpımı (GSYİH'ya oran) }\end{array}$ & Database 2016 \\
\hline
\end{tabular}

Konuyla ilgili literatürde göçmen gönderilerinin giriş yaptığı ülkede gelir seviyesini artırıcı ve döviz kıtlığını azaltarak ödemeler dengesi ve dış ticaret açıklarını kapatıcı fonksiyonlarına vurgu yapılmaktadır (OECD, 2006: 156). Ancak göçmen gönderilerinin büyük bir kısmı tüketim veya arsa-ev alımı gibi kişisel yatırım amaçlarıyla kullanıldığ durumlarda uzun dönem büyüme performansına olumlu etkisi yerine daha çok dış ticaret açıklarını artırıcı etkisi ortaya çıkar (Giuliano ve Ruiz-Arranz, 2005: 3). Bu durumda göçmen gönderilerinin uzun dönemde dış denge üzerine etkisini gösteren $\beta_{1}$ katsayısı negatif değer alacaktır.

İthalat fonksiyonuna göre kişi başı gelirin yükselmesi, ithalatı artırarak dış denge üzerinde olumsuz etkiler ortaya çıkaracaktır. Böylesi bir durumda ekonomik gelişmişliği temsil eden GROWTH değişkeninin uzun dönemde negatif işaret alması beklenir $\left(\beta_{2}<0\right)$. GROWTH değişkeninin pozitif işaret alması durumunda ülkenin ihracata dayalı bir büyüme politikası izlediği yorumu yapılabilecektir (Bahmani- Oskooee ve Wang, 2006: 326).

Literatürde en yaygın kullanılan finansal gelişmişlik göstergelerden biri özel sektör kredilerinin GSYİH içindeki payıdır (FINDEV) (Khan ve Senhadji, 2003: 92). Gelişmiş finansal sistemin varlığında işlem maliyetleri küçük boyutlarda olacağ için göçmenler anavatanlarına para transferi için ulusal finans sistemini kullanacaklardır. Finansal sistemin gelişmediği ülkelerde ise göçmenler, yasal olmayan kanallar ile para gönderimine yöneleceklerdir. Ayrıca yurtiçi finans piyasalarının gelişmediği ülkelerde göçmen gönderileri, likidite darlığını gidermeye yardımcı olmakta ve bu yönüyle ekonomik aktörlerin yatırım veya tüketim harcamalarına fon sağlayarak bankacılık sektöründen alınabilecek özel kredilerin ikamesi olabilmektedir (Giuliano ve Ruiz-Arranz, 2005: 5-6). Ancak finans piyasalarının geliştiği ülkelerde bireyler kolayca kredi alma imkanına sahip olacağı için göçmen gönderileri tüketim ve yatırım harcamalarının finansmanında önemini yitirecektir (Ramirez ve Sharma, 2009: 9). Uzun dönem denkleminde yer alan REM * FINDEV etkileşim terimi, Giuliano ve Ruiz-Arranz (2005), Ramirez ve Sharma (2009) çalışmalarından hareketle, göçmen gönderilerinin bankacılık 
sektörü kredilerinin ikamesi olup olmadığını belirlemek üzere oluşturulmuştur. Bu değişkenin negatif işaret alması, ilgili ülkede finansal sistemin az gelişmiş bir yapıda olduğu ve bu nedenle göçmen gönderileri ve yurtiçi kredilerin birbirinin ikamesi gibi işlev gördüğü anlamına gelecektir (Ramirez ve Sharma, 2009: 16).

\section{METODOLOJİ VE AMPIRIK BULGULAR}

Uzun dönemde değişkenlerin birlikte hareket ettiklerine yönelik bir çıkarım yapılabilmesi için eş-bütünleşme yöntemleri kullanılmaktadır. Ancak eşbütünleşme ilişkisinin varlığını araştırmadan önce aralarında ilişki olduğuna yönelik teorik dayanağın olduğu değişkenlerin entegrasyon düzeylerinin belirlenmesi bir diğer ifadeyle durağanlık düzeylerinin tespiti gerekmektedir. Durağanlık analizi yapmak üzere geliştirilen yöntemler birinci nesil ve ikinci nesil birim kök testleri olarak sınıflanmaktadır. Böylesi bir ayrıma gidilmesindeki temel neden, paneli oluşturan yatay kesit birimleri arasında bağımlılığın varlığından kaynaklanır. Birinci nesil birim kök yöntemlerinden yaygın olarak kullanılan Maddala ve Wu (1999), Breitung (2000), Hadri (2000), Choi (2001), Levin vd. (2002) ve Im vd. (2003) yatay kesit bağımlılığını dikkate almamasına rağmen ikinci nesil yöntemlerden Pesaran (2007) CADF ve CIPS (cross-sectionally augmented IPS) ile Hadri ve Kurozumi (2012) yatay kesit bağımlılı̆̆ını dikkate almaktadır.

Değişkenlerin entegrasyon düzeylerini belirlemek üzere kullanılacak olan birim kök yöntemlerinin yatay kesit bağımlılığına göre farklılaştığı hususu dikkate alındığında birim kök analizinden önce değişkenler ve eş-bütünleşme denkleminde yatay kesit bağımlılığının varlığı araştırılmalıdır. Yatay kesit bağımlılığının bulunduğu örneklerde bu durumu dikkate almayan yöntemlerin kullanılması ulaşılan sonuçların güvenilirliğini azaltacaktır. Bu çalışmada yatay kesit birimleri arasında bağımlılığının varlığını test etmek üzere Breusch ve Pagan (1980) LM (Lagrange Multiplier) ile Pesaran vd. (2008) tarafından geliştirilen sapması düzeltilmiş LM ( $L M_{\text {adj. }}$ ) testi kullanılmıştır. Breusch ve Pagan (1980) LM istatistiği, yatay kesit biriminin zaman boyutundan nispeten küçük olduğu panellerde daha anlamlı sonuçlar verirken (sabit $\mathrm{N}$ ve $\mathrm{T} \rightarrow \infty$ ), $L M_{a d j}$. istatistiği hem zaman hem de yatay kesit boyutunun büyük olduğu panellerde $(\mathrm{T} \rightarrow \infty$ ve $\mathrm{N} \rightarrow \infty)$ kullanılabilmektedir. Boş hipotezde yatay kesit bağımsızlı̆̆ını sınayan bu iki istatistik sırasıyla Eşitlik 2 ve 3 kullanılarak elde edilmektedir (Pesaran, 2004: 1-4; Pesaran vd., 2008: 108).

$$
\begin{aligned}
& L M=T \sum_{i=1}^{N-1} \sum_{j=i+1}^{N} \hat{\rho}_{i j}^{2} \\
& L M_{a d j}=\sqrt{\frac{2}{N(N-1)} \sum_{i=1}^{N-1} \sum_{j=i+1}^{N} \frac{(T-k) \hat{\rho}_{i j}^{2}-\mu_{T i j}}{\vartheta_{T i j}}}
\end{aligned}
$$


Yatay kesit bağımlılığının varlığını test etmek için uygulanan Breusch ve Pagan (1980) $L M$ ve Pesaran vd. (2008) $L M_{a d j}$ test sonuçları Tablo 2'de sunulmuştur. Tabloda yer alan bulgular yatay kesit bağımsızlı̆̆ını belirten boş hipotezin her bir değişken ve uzun dönem denklemi için \%99 önem düzeyinde kabul edildiğini göstermektedir. $\mathrm{Bu}$ sonuca göre panelde yer alan bağımsız devletler topluluğu üyesi 6 ülkeden herhangi birinde ortaya çıkacak bir şokun diğer ülkelerde benzer bir etki yaratmayacağı yorumu yapılabilecektir.

Tablo 2. Yatay Kesit Bağımlılı̆̆ Testi

\begin{tabular}{lcccc}
\hline & \multicolumn{2}{c}{ Breusch ve Pagan (1980) } & LM Testi & \multicolumn{2}{c}{ Pesaran vd. (2008) LM $_{\text {adj }}$} \\
\hline Değişken & İstatistik & Olasılık değeri & İstatistik & Olasılık değeri \\
\hline TB & 29.619 & 0.02 & 0.636 & 0.26 \\
REM & 23.432 & 0.08 & 3.756 & 0.01 \\
GROWTH & 33.240 & 0.01 & -0.658 & 0.74 \\
EXC & 29.863 & 0.02 & -1.514 & 0.93 \\
REM $*$ FINDEV & 28.187 & 0.02 & 0.605 & 0.27 \\
Eşitlik & 33.553 & 0.01 & -0.079 & 0.53 \\
\hline
\end{tabular}

Uzun dönem denkleminde yer alan bağımlı ve bağımsız değişkenlerin durağanlık mertebelerini tespit etmek üzere boş hipotezde serinin durağan olmadığını sınayan Levin vd. (LLC) (2002), Im vd. (IPS) (2003), Maddala ve Wu (1999) ADF Fisher ve PP Fisher birim kök yöntemleri uygulanmıştır. Bu yöntemlerin yanısıra boş hipotezde serinin durağan olduğunu ifade eden Hadri (2000) birim kök testi ile de durağanlık sınaması yapılmış ve elde edilen bulgular Tablo 3 'te raporlanmıştır.

Tablo 3: Panel Birim Kök Test Sonuçları

\begin{tabular}{|c|c|c|c|c|c|}
\hline \multirow{2}{*}{ Değişken } & \multicolumn{4}{|c|}{$H_{0}$ : Seri durağan değildir. } & \multirow{2}{*}{$\frac{\mathrm{H}_{\mathrm{o}} \text { :Seri durağand }}{\text { Hadri }}$} \\
\hline & LLC & IPS & ADF Fisher & PP Fisher & \\
\hline TB & $-1.26(0.11)$ & $1.26(0.89)$ & $4.95(0.95)$ & $6.47(0.89)$ & $4.70(0.00)$ \\
\hline REM & $0.35(0.63)$ & $0.72(0.76)$ & $8.17(0.77)$ & $23.4(0.03)$ & $4.92(0.00)$ \\
\hline GROWTH & $-3.11(0.00)$ & $-1.44(0.07)$ & $17.3(0.13)$ & $48.7(0.00)$ & $2.98(0.00)$ \\
\hline EXC & $9.44(0.99)$ & $5.36(0.99)$ & $0.52(0.99)$ & $0.01(0.99)$ & $6.40(0.00)$ \\
\hline REM * FINDEV & $0.69(0.75)$ & $0.75(0.77)$ & $6.71(0.87)$ & $15.7(0.20)$ & $4.53(0.00)$ \\
\hline$\Delta \mathrm{TB}$ & $-2.55(0.00)$ & $-1.89(0.02)$ & $21.4(0.04)$ & $52.8(0.00)$ & $1.50(0.07)$ \\
\hline$\triangle \mathrm{REM}$ & $0.66(0.74)$ & $-1.43(0.07)$ & $17.6(0.12)$ & $59.9(0.00)$ & $2.77(0.02)$ \\
\hline$\triangle \mathrm{GROWTH}$ & $-2.38(0.00)$ & $-3.19(0.00)$ & $30.1(0.00)$ & $95.8(0.00)$ & $0.33(0.36)$ \\
\hline$\Delta \mathrm{EXC}$ & $0.13(0.05)$ & $-1.30(0.09)$ & $24.9(0.01)$ & $48.1(0.00)$ & $3.87(0.01)$ \\
\hline$\triangle$ REM $*$ FINDEV & $-1.69(0.04)$ & $-2.35(0.00)$ & $24.5(0.01)$ & $51.6(0.00)$ & $2.96(0.01)$ \\
\hline
\end{tabular}

Not: $\Delta$ serilerin birinci farkının alındığını gösteren işlemcidir. Olasılık değerleri parantez içinde verilmiştir. Birim kök testleri, değişkenlerin sabitli ve trendli model formuna uygulanmıştır.

Tablo 3'te yer alan bulgular TB, REM,EXC, REM *FINDEV değişkenlerinin seviye düzeyinde beş birim kök yönteminin hepsine göre \%99 önem düzeyinde birim kök içerdiğini göstermektedir. Ekonomik gelişmişlik düzeyini temsil eden GROWTH değişkeni ise LLC ve PP Fisher birim kök 
yöntemlerine göre seviye değerinde durağan iken diğer üç birim kök testine göre birim köke sahiptir. Bu sonuçlara göre tüm değişkenler beş birim kök yönteminin en az üçüne göre seviye düzeyinde durağan değildir ve birim kök içermektedir. Serilerin birinci farklarında durağanlık yapılarını araştırmak için yeniden analiz yapıldığında ise değişkenlerin durağanlaştığı bir diğer ifadeyle I(1) olduğu gözlenmiştir.

Değişkenlerin tümünün birinci farkında bütünleşik olduklarının tespitinin ardından bir sonraki aşamada bu değişkenler arasında eş-bütünleşme ilişkisinin varlığı araştırılacaktır. Yatay kesit bağımsızlığı altında en yaygın kullanılan yöntemler Pedroni (1999, 2004), Kao (1999) ve Maddala ve Wu (1999) JohansenFisher eş-bütünleşme testleridir. $\mathrm{Bu}$ yöntemlerin tümü, boş hipotezde seriler arasında uzun dönem ilişkinin olmadığını, alternatif hipotezde ise varlığını sınamaktadır. Ancak Johansen-Fisher yöntemi, incelenen değişkenler arasında birden fazla eş-bütünleşme ilişkisinin varlığını test etmesi yönüyle diğer iki yöntemden farklılaşmaktadır. Bu çalışmada bağımlı ve bağımsız değişkenler arasında uzun dönem ilişkinin varlığını araştırmak üzere Johansen metodolojisine dayanan Fisher tipi eş-bütünleşme yöntemi tercih edilmiştir.

Johansen (1988), seviyede durağan olmayan seriler arasında uzun dönemde ilişkinin varlığını araştırmak üzere iz testi ve maksimum özdeğer testinden elde edilmek üzere iki adet Fisher istatistiği hesaplamaktadır. Elde edilen Fisher istatistiklerine ait olasıl1k değerinin \%99 önem düzeyinde 0.01 'den, \%95 önem düzeyinde 0.05 'ten, \%90 önem düzeyinde ise 0.10 'dan küçük olduğu durumlarda boş hipotez reddedilecek ve eş-bütünleşme ilişkisinin olduğu çıkarımı yapılacaktır.

Tablo 4: Fisher Eş-bütünleşme Test Sonuçları

\begin{tabular}{ccccc}
\hline Boş Hipotezi & $\begin{array}{c}\text { Trace Testi } \\
\text { Fisher istatistiği }\end{array}$ & $\begin{array}{c}\text { Olasılık } \\
\text { değeri }\end{array}$ & $\begin{array}{c}\text { Max-eigen Testi } \\
\text { Fisher İstatistiği }\end{array}$ & Olasılık değeri \\
\hline $\mathrm{r}=0$ & $72.38^{* *}$ & 0.03 & $33.91^{* * *}$ & 0.04 \\
$\mathrm{r} \leq 1$ & 38.46 & 0.28 & 24.26 & 0.12 \\
$\mathrm{r} \leq 2$ & 14.19 & 0.82 & 7.602 & 0.92 \\
$\mathrm{r} \leq 3$ & 6.591 & 0.62 & 4.877 & 0.75 \\
$\mathrm{r} \leq 4$ & 1.713 & 0.19 & 1.713 & 0.19 \\
\hline
\end{tabular}

Not: ***, ** ve * eş-bütünleşme ilişkisinin olmadığını belirten boş hipotezin sırasıyla \%99, 95 ve 90 önem düzeyinde reddedildiğini ifade etmektedir. Doğrusal deterministik trend varsayımı dikkate alınmış ve olasılık değerleri asimtotik ki-kare dağılımı kullanılarak hesaplanmıştır.

Eşitlik 1'deki değişkenlere uygulanan Johansen-Fisher eş-bütünleşme testi sonuçları Tablo 4'te sunulmuştur. Bulgular incelendiğinde iz istatistiği ve maksimum özdeğer istatistiklerinin her ikisine göre eş-bütünleşmenin olmadığını belirten boş hipotezin \%95 önem düzeyinde reddedildiği görülmektedir. $\mathrm{Bu}$ doğrultuda Johansen metodolojisinin izlendiği Fisher eş-bütünleşme testi, $T B, R E M, E X C, G R O W T H, R E M * F I N D E V$ değişkenlerin uzun dönemde birlikte hareket ettiklerini ve \%95 önem düzeyinde bu değişkenler arasında en az bir tane eş-bütünleşme denklemi olduğunu ortaya koymaktadır.

Eşitlik 1'de yer alan değişkenlerin eş-bütünleşik olduklarının tespit edilmesinin ardından bağımsız değiş̧kenlerin uzun dönemde alacağ 1 katsayılara ulaşmak için Pesaran, Shin ve Smith (1999) tarafından geliştirilen havuzlanmış 
ortalama grup (PMG - Pooled Mean Group) tahmincisi kullanılmıştır. PMG tahmincilerine ait sonuçlar Tablo 5'te gösterilmiştir.

Tablo 5. PMG (panel mean group) Tahmin Sonuçları

\begin{tabular}{lcccc}
\hline \multicolumn{1}{c}{ Ülke } & REM & GROWTH & EXC & REM * FINDEV \\
\hline Azerbaycan & $18.681 * * *$ & 0.725 & $-141.1 * *$ & $0.622 * *$ \\
Kazakistan & 103.15 & 3.012 & -0.452 & -1.865 \\
Kirgizistan & 8.779 & -7.622 & 7.036 & -0.800 \\
Moldova & $-1.258 * *$ & -0.073 & 0.153 & -0.009 \\
Tacikistan & $-0.851 * * *$ & -1.439 & $-2.455^{* *}$ & $-0.020^{*}$ \\
Ukrayna & 1.619 & -0.516 & -0.990 & -0.051 \\
PANEL & $-0.908 * * *$ & 0.331 & $-0.122 * *$ & $-0.010^{* * *}$ \\
\hline
\end{tabular}

Not: *, ** ve *** sirasıyla \%90, 95 ve 99 önem düzeyinde anlamlılı̆̆ ifade etmektedir.

PMG yöntemi uzun dönem katsayı tahminlerine göre göçmen gönderileri $(R E M)$ bağımsız devletler topluluğuna üye 6 ülkenin dördünde dış ticaret dengesini $(T B)$ pozitif yönde, diğer iki ülkede ise negatif yönde etkilemektedir. Ancak bu sonuçlardan üç ülkeye ait bulgular istatistiksel açıdan anlamlıdır. Göçmen gönderisi girişleri yalnızca Azerbaycan'ın dış ticaret dengesi üzerinde istatistiksel açıdan anlamlı iyileştirici etkiye sahip iken Moldova ve Tacikistan'a gelen göçmen havaleleri, bu ülkelerin diş ticaret dengesinde bozucu etkiler yaratmaktadır. Bu doğrultuda göçmen gönderilerinin panelde yer alan altı ülkeden yalnızca Azerbaycan'da dış ticaret açığının azalmasına yardımcı olduğu, Moldova ve Tacikistan'da ise daha çok tüketim veya ithalatın finansmanı amacıyla kullanılmasından dolayı dış dengeyi olumsuz yönde etkilediği yorumu yapılabilecektir.

$R E M * F I N D E V$ etkileşim terimi, panelde yer alan beş ülkede negatif işaret almasına rağmen yalnızca Tacikistan'da \%10 önem düzeyinde anlamlılığa sahiptir. Bu sonuca göre göçmen gönderileri Tacikistan'da bankacılık sektörü kredilerinin ikamesi olmakta ve ithalat harcamalarına kaynak oluşturması nedeniyle dış ticaret dengesini olumsuz yönde etkilemektedir. REM * FINDEV değişkeninin Azerbaycan'da aldığı pozitif ve anlamlı katsayı ise finansal sistemin Azerbaycan'da yatırım ve tüketim harcamalarını fonlama fonksiyonunu yerine getirdiğini ortaya koymaktadır.

Ekonomik gelişmişlik düzeyini temsil eden GROWTH değişkeni ise paneldeki altı ülkenin dördünde negatif, iki ülkede ise pozitif işaret almasına rağmen bu sonuçların hiçbiri istatistiksel anlamlılığa sahip değildir. Bunun yanı sıra ulusal paranın ABD doları karşısındaki değerini ve ülkenin dış ticarette rekabet edilebilirlik gücünü gösteren $E X C$ değişkeni Azerbaycan ve Ukrayna'da istatistiksel olarak anlamlı negatif katsayı almaktadır.

\section{SONUÇ}

$\mathrm{Bu}$ çalışma, Bağımsız Devletler Topluluğu üyelerinden 2002-2016 döneminde kesintisiz verisine ulaşılabilen altı ülkede göçmen gönderilerinin dış ticaret dengesi üzerine etkisini panel veri analiz yöntemleri ile araştırmayı amaçlamaktadır. Panel Azerbaycan, Kazakistan, Kırgızistan, Moldova, Ukrayna ve Tacikistan'dan oluşmaktadır. Ekonometrik analiz öncesinde değişkenler ve uzun 
dönem denkleminde yatay kesit bağımlılığının varlığı araştırılmıştır. Yapılan testler sonucunda panelde yer alan altı ülkede yatay kesit bağımsızlı̆̆ı olduğunun belirlenmesi üzerine birim kök, eş-bütünleşme ve tahminci yöntemleri olarak birinci nesil metotlar tercih edilmiştir.

Uzun dönemde değişkenlerin aldığı katsayıları tahmin etmek için Pesaran, Shin ve Smith (1999) tarafından geliştirilen havuzlanmış ortalama grup (PMG Pooled Mean Group) tahmincisi kullanılmıştır. PMG tahmincisi ile ulaşılan bulgular göçmen gönderilerinin dış ticaret dengesini Azerbaycan'da pozitif; Moldova ve Tacikistan'da ise negatif yönde etkileyen anlamlı bir değişken olduğunu ortaya koymaktadır. Bu doğrultuda göçmen gönderilerinin panelde yer alan altı ülkeden yalnızca Azerbaycan'da diş ticaret dengesine katkı sağladığ görülmektedir. Bu sonuç Bouhga-Hagbe(2004)’ün Fas için yaptığı çalışmanın bulguları ile örtüşmektedir. Diğer yandan Nayyar (1994), Buch ve Kuckulenz (2004) ve Kandil ve Mirzaie (2008)'in savlarını destekler niteliktedir. Moldova ve Tacikistan'a ilişkin bulgular ise göçmen gönderilerinin iki ülkede çoğunlukla tüketim veya ithalatın finansmanı amacıyla kullanıldığını ve bu nedenle ülkelerin diş ticaret dengesini olumsuz etkilediğini göstermiştir. Bu iki ülkeye yönelik sonuçlar ise Gençler ve Çiftçi(2012)'nin Türkiye için, Okodua ve Olayiwola (2013)'ün Sahra altı Afrika ülkeleri için ve Farzanegan ve Hassan(2015)'in Orta Doğu ve Kuzey Afrika ülkeleri için yaptıkları çalışmaların bulguları ile örtüşmektedir. $\mathrm{Bu}$ çalışma ile ulaşılan bir diğer önemli bulgu ise göçmen gönderileri ve ülkenin finansal gelişmişlik düzeyi ile ilgilidir. Göçmen gönderilerinin Tacikistan'da bankacılık sektörü kredilerinin ikamesi bir parasal kaynak olarak ithalatı finanse ettiği buna karşın Azerbaycan'da yatırım ve tüketim harcamalarını fonlama fonksiyonunu yerine getirdiği tespit edilmiştir

Gönderiler uzun dönemde tasarruf kanalı ile kurumların üretimlerini finanse ederek ihracatı teşvik eder ve dış ticaret açı̆̆ının kapanmasını sağlayabilirken diğger yandan gelir artışı nedeniyle oluşan ek talep ülke üretimi ile karşılanamadığ 1 durumda ithalatı da artırabilmektedir. Gönderilerin uzun dönemde dış ticaret dengesini etkileme yönü, bu gönderilerin alıcı ülkede ne şekilde kullanıldığı ile ilgilidir. Dolayısıyla yüksek göçmen havalesi alan ülkelerin tasarrufları ve dolayısıyla yatırımları pozitif yönde etkileyecek şekilde değerlendirilmesini sağlayacak politikaları hayata geçirmesi büyük önem taşımaktadır.

\section{KAYNAKÇA}

Acosta, P., P. Fajnzylber ve J.H. Lopez, 2007, "The impact of remittances on poverty and human capital: evidence from Latin American household surveys ", World Bank Policy Research Working Paper,4247, WPS4247.

Adams, R.H., 1991, "The effect of international remittances on poverty, inequality and development in rural Egypt", Research Report 86, International Food Policy Research Institute, Washington DC.

Adams, R.H. ve J. Page, 2003, "International migration remittances and poverty in developing countries", Policy Research Working Paper, No:3179, Washington, DC.

Ahlburg, D.A, 1996, "Remittances and the income distribution in Tonga", Population Research and Policy Review, 15(4), 391-400. 
Amuedo-Dorantes, C. and S. Pozo, 2004, "Workers'remittances and the real exchange rate: a paradox of gifts", World Development, 32(8), 1407-1417.

Acharya, C. P., ve Leon-Gonzalez, R. 2013, "The impact of remittance on poverty and inequality: A micro-simulation study for Nepal”, Asian Journal of Empirical Research, 3(9), 1061-1080.

Bahmani-Oskooee, M. ve Wang, Y. 2006, "The J-curve: China versus her trading partners", Bulletin of Economic Research, Vol.58, 323-343.

Breusch, T. S. ve Pagan, A.R. 1980,'The lagrange multiplier test and its applications to model specification in econometrics" Review of Economic Studies, 47, 239-253.

Breitung, J. 2000, The Local Power of Some Unit Root Tests For Panel Data, in: B. Baltagi (ed.), Nonstationary Panels, Panel Cointegration, and Dynamic Panels, Advances in Econometrics, Vol. 15, JAI: Amsterdam, 2000, p. 161- 178.

Brown R.P.C ve D.A. Ahlburg, 1999, "Remittances in the south pacific", International Journal of Social Economics, 26(1/2/3), 325-344

Bouhga-Hagbe, J. ,2004, “A theory of workers' remittances with an application to Morocco", IMF Working Paper, WP/04/194.

Buch, C., A. Kuckulenz ve M. Le Manchec, 2002, "Worker remittances and capital flows", Kiel Working Paper, No: 1130, Kiel Institute for World Economics, Kiel.

Buch, C.M. ve A. Kuckulenz, 2004, "Worker remittances and capital flows to developing countries", ZEW-Centre for Europan Economic Research Discussion Paper, No.04-031.

Chami, R., C. Fullenkamp, ve S. Jahjah. 2003. "Are 1mmigrant remittance flows a source of capital for development?”, IMF Working Paper WP/03/190, IMF Institute, Washington, DC.

Choi, I. 2001, Unit root tests for panel data, Journal of International Money and Finance, $20,249-72$.

El-Sakka, M.I.T. ve R. McNabb, 1999, "The macroeconomic determinants of emigrant remittances", World Development, 27(8), 1493-1502.

Farzanegan, M.R. ve S.M. Hassan, 2016, "How does the flow of remittances affect the trade balance of the middle east and north africa", Macie Paper Series, Marburg Centre for Institutional Economics, No:2016/13.

Fuentes, J., ve Herrera, J.C. (2007). Emigrant Remittances and the Real Exchange Rate in Guatemala: An Adjustment-Costs Story. Guatemala: Bank of Guatemala.

Gençler, A. ve Çiftçi, M. 2012, “Dış Ticaretin Finansmanında Göçmen Gönderilerinin Rolü: Türkiye Örneği” Sosyoekonomi, 17(17), 301-331

Giuliano, P. ve R. Marta, 2005, Remittances, Financial Development, and Growth. IMF Working Paper Research Department, WP/05/234.

Hadri, K. 2000, Testing for stationarity in heterogeneous panel data. Journal of Econometrics, 3, 148 161.

Hadri, K. ve Kurozumi, E. 2012, A simple panel stationarity test in the presence of serial correlation and a common factor, Economics Letters 115, 31-34.

Im, K. S., Pesaran, M. H. ve Shin, Y. 2003, Testing for unit roots in heterogeneous panels, Journal of Econometrics, 115, 53-74.

Johansen,S. 1988, Statistical analysis of cointegration vectors .Journal of Economic Dynamics and Control,12, 231-254.

Kandil, M., ve I. Mirzaie, 2008, "The impact of capital and remittance flows on economic performance in mena countries, World Economics, 10(3), 159-192.

Kao, C. 1999, Spurious Regression and Residual-based Tests for Co-integration in Panel Data. Journal of Econometrics, Vol. 90, No.1, 1-44.

Khan, M.S. ve Senhadji, A.S., 2003. Financial development and economic growth: a review and new evidence. Journal of African Economies 12 (supp 2), 89-110.

Levin, A., Lin, C. F. ve Chu, C. S. J. 2002, Unit root test in panel data: asymptotic and finite sample properties, Journal of Econometrics, 108, 1-24.

Lipton, M., 1980, Migration from rural areas of poor countries: the 1mpact on rural productivity and income distribution, World Development, 8(1), 1-24. 
Leon-Ledesma, M. ve M. Piracha, 2004, "International migration and the role of remittances in eastern europe", International Migration, 42(4), 65-83.

Lopez, H., L. Molina ve M. Bussolo, 2007, "Remittances and the real exchange rate." World Bank, Washington, DC.

Lowell, B. Lindsay ve R. de la Garza, 2000, "The developmental role of remittances in u.s. latino communities and in latin american countries ", A Report of the Tomás Rivera Policy Institute and the Inter-American Dialogue, http://www.thedialogue.org

Maddala, G. S. ve Wu, S. 1999, "A comparative study of unit root tests with panel data and a new simple test", Oxford Bulletin of Economics and Statistics, special issue, 631-652.

Migration and Development Brief 27, April 2017.

Nayyar, D. 1994, "Migration, remittances and capital flows: the Indian experience", Oxford University Press, UK.

Nsiah, C. ve B. Fayissa, 2013, "Remittances and economic growth in africa, asia and latin americancaribbean countries: a panel unit root and panel cointegration analysis", Journal of Economics and Finance, 37(3), 424-441.

Okodua, H. ve W. K. Olayiwola, 2013, "Migrant workers' remittances and external trade balance in Sub-Sahara African countries", International Journal of Economics and Finance, 5(3), 134142.

OECD (2006). International Migrant Remittances and their Role in Development. International Migration Outlook Part III, pp. 139-161. https://www.oecd.org/els/mig/38840502.pdf

Pedroni, P. 1999, "Critical values for cointegration tests in heterogeneous panels with multiple regressors", Oxford Bulletin of Economics and Statistics 61, 653-670.

Pedroni, P. 2004, Panel cointegration: asymptotic and finite sample properties of pooled time series tests with an application to the PPP hypothesis: new results. Econometric Theory 20, $597-$ 627.

Pesaran, M.H. 2007, A simple unit root test in the presence of cross-section dependence, Journal of Applied Econometrics, 22 (2), 265-312.

Pesaran, H., Ullah, A. ve Yamagata, T. 2008, A bias-adjusted LM test of error crosssection independence. Econometrics Journal 11, 105-127.

Pesaran, M. H., Shin, Y. ve Smith, R. J. 1999, Pooled Mean Group Estimation of Dynamic Heterogeneous Panels, Journal of the American Statistical Association, 94, 621-634.

Ramirez, M. ve S. Hari, 2009, Remittances and growth in Latin America: a panel unit root and panel cointegration analysis. EEDI-ESID. Economic Studies of International Development 9(1), $5-36$.

Ratha, D. 2004, “The development dimension of remittances", IOM Working Paper Series, No:1, Department of Migration Policy, Research and Communications. http://www.iom.int/documents/publication/en/mpr1.pdf

Rosser, E., 2008, “ Immigrant remittances”, Connecticut Law Review, 41(1), 1-61.

Shaw, J. (ed) ,2006, "Remittances microfinance and development: building the links", 1, A Global View, The Foundation for Development Cooperation, Brisbane.

Sorensen, N. N., 2004, "The development dimension of migrant remittances." IOM Working Paper Series No. 1, June, IOM, Geneva.

Taylor, J. Edward ve T.J. Wyatt, 1996, "The shadow value of migrant remittances, income and inequality in a household-farm economy." Journal of Development Studies, 32(6), 899912.

Taylor, J. Edward, 1999, "The new economics of labour migration and the role of remittances in the migration process." International Migration, 37(1), 63-88

\section{SUMMARY}

This study aims to investigate the impact of remittances on balance of foreign trade in six member countries of the Commonwealth of Independent States for the period of 2002-2016. The study uses panel data analysis methods, and the panel consists of Azerbaijan, Kazakhstan, Kyrgyzstan, Moldova, Ukraine, and 
Tajikistan. Prior to the econometric analysis, the existences of cross-sectional dependence in the long-term equation were investigated. As a result of the tests, cross-sectional independence was observed in the six countries in the panel, and thus, the first generation methods were opted for as unit root, co-integration and parameter estimation methods.

In order to estimate the coefficients of the variables in the long term, the pooled mean group (PMG) estimator developed by Pesaran, Shin and Smith (1999) was used. The findings obtained with the PMG estimator revealed that remittances had a positive impact on balance of foreign trade in Azerbaijan, while in Moldova and Tajikistan, remittances were found to be a significant variable that affected balance of foreign trade negatively. In this respect, it is seen that remittances have contributed to balance of foreign trade only in Azerbaijan among the six countries in the panel. This result coincides with the findings of the study conducted by Bouhga-Hagbe (2004) for Morocco. Furthermore, it seems to support the hypotheses of Nayyar (1994), Buch and Kuckulenz (2004), and Kandil and Mirzaie (2008). On the other hand, the findings pertaining to Moldova and Tajikistan show that in both countries, remittances are mainly used for financing consumption or import, which affects their balance of foreign trade negatively. The findings for these two countries coincide with the findings of Gençler and Çiftçi (2012) for Turkey, Okodu and Olayiwola (2013) for sub-Saharan African countries, and Farzanegan and Hassan (2015) for the Middle East and North African countries. Another important finding obtained from this study is related to remittances and the financial development. Our study revealed that remittances financed import in Tajikistan as a monetary resource to substitute for banking sector loans, while the remittances have the function of funding investment and consumption expenditures in Azerbaijan.

In the long-term, remittances encourage export by financing the production of firms through savings. While they help reduce foreign trade deficit, they also increase import when the additional demand that surfaces due to the increase in revenue cannot be met with country's production. The way remittances affect foreign trade balance in the long-term is related to how these remittances are used in the recipient country. Therefore, it is of great importance to implement policies which will enable the countries which receive high amount of remittances to be evaluated in a way that will affect the savings and thus the investments in a positive way. 